\title{
MODEL REGRESI NONPARAMETRIK BERDASARKAN ESTIMATOR POLINOMIAL LOKAL KERNEL PADA KASUS PERTUMBUHAN BALITA DI KOTA PADANG
}

\author{
RESTY OKTAVIANI, HAZMIRA YOZZA, YUDIANTRI ASDI \\ Program Studi S1 Matematika, \\ Fakultas Matematika dan Ilmu Pengetahuan Alam, Universitas Andalas, \\ Kampus UNAND Limau Manis Padang, Indonesia. \\ email : resty251097@gmail.com, hazmirayozza@sci.unand.ac.id,yudiantriasdi@sci.unand.ac.id
}

\begin{abstract}
Abstrak. Balita adalah istilah untuk anak usia dibawah 5 tahun yaitu 1-3 tahun (batita) dan anak prasekolah (3-5) tahun. Masa balita merupakan periode terpenting dalam proses tumbuh kembang manusia, terutama pada 1000 hari pertama pada kehidupan. Oleh karena itu, pola pengasuhan yang baik dan benar serta pemantauan pertumbuhan balita sangat dibutuhkan. Pemantauan gizi balita akan dibandingkan dengan suatu acuan yaitu kurva pertumbuhan dengan mengetahui bentuk hubungan antara berat badan balita dan umur. Hubungan ini akan dimodelkan dengan regresi nonparametrik dengan penduga polinomial lokal kernel, dimana fungsi kernel yang digunakan adalah Gaussian dan penduga kuadrat terkecil. Penduga kernel ini sangat bergantung pada pemilihan bandwidth yang digunakan yaitu metode complete cross validation dan diperoleh nilai bandwidth sebesar 3,059628 dengan meminimumkan weighted least square. Pemilihan model terbaik antara penduga kuadrat terkecil dan penduga kernel polinomial lokal berdasarkan kriteria koefisien determinasi. Nilai koefisien determinasi dari penduga kuadrat terkecil adalah 0,93144 dan nilai koefisien determinasi penduga kernel polinomial lokal adalah 0,954367 .
\end{abstract}

Kata Kunci: Nonparametrik, Estimator Polinomial Lokal, Kernel Gaussian, Complete Cross Validation, Weighted Least Square

\section{Pendahuluan}

\subsection{Pertumbuhan dan Perkembangan}

Pertumbuhan balita dikatakan baik jika berat badannya seimbang dengan umur, tinggi badan dan lingkar kepalanya [1]. Secara umum, berat badan menurut umur merupakan indikator global keadaan gizi, sedangkan tinggi badan menurut umur merefleksikan riwayat gizi masa lalu. Penggunaan keduanya merupakan upaya yang baik untuk menaksir keadaan gizi masa kini dan masa lalu. Namun pengukuran berat badan menurut umur memiliki keuntungan, yaitu pengukurannya yang mudah dilaksanakan dan teliti, pengukuran tidak memakan waktu yang lama, pengukuran

*penulis korespondensi 
objektif dan bila diulang memberikan hasil yang sama, sensitif terhadap perubahan keadaan gizi yang kecil serta peralatannya yang dapat dibawa dengan mudah.

Kurva pertumbuhan merupakan hubungan antara berat badan menurut umur. Dalam statistika hubungan antara 2 variabel dapat diduga dengan analisis regresi. Pendugaan ini dapat dilakukan dengan berbagai teknik regresi, yaitu regresi parametrik, regresi nonparametrik dan regresi semiparametrik, yang masingmasingnya mempunyai aturan yang berbeda. Pada regresi parametrik dan semiparametrik bentuk hubungan antara variabel respon dan prediktor diketahui artinya kurva pada regresi tersebut telah diketahui bentuknya. Regresi nonparametrik juga dapat digunakan untuk memodelkan hubungan antara variabel respon dan prediktor yang belum diketahui artinya tidak tergantung bentuk kurva pada regresi tersebut.

Model regresi nonparametrik dapat berbentuk fungsi apapun, baik linear atau non linear. Fungsi dari regresi ini dapat diduga berdasarkan data dengan menggunakan teknik pemulusan. Pada penelitian ini akan digunakan salah satu teknik pemulusan yaitu penduga kernel. Pemulusan dengan menggunakan penduga kernel lebih fleksibel dan memiliki kemampuan yang baik dalam memodelkan data yang tidak memiliki pola tertentu. Pemulusan dengan menggunakan pendugaan kernel tergantung pada fungsi kernel dan nilai bandwidth [5]. Salah satu fungsi kernel yang dapat digunakan aadalah fungsi kernel Gaussian dengan penduga polinomial lokal. Penduga polinomial lokal dapat diperoleh dengan optimasi WLS ( Weight Least Square), sedangkan untuk mengestimasi parameter penghalus (bandwidth) dilakukan dengan menggunakan Metode CCV (Complate Cross Validation).

\section{Landasan Teori}

\subsection{Regresi Nonparametrik}

Regresi nonparametrik digunakan untuk mengetahui pola hubungan antara variabel prediktor dengan variabel respon ketika tidak diperoleh informasi tentang bentuk fungsi regresinya. Keuntungan menggunakan metode regresi nonparametrik dibandingkan dengan regresi parametrik adalah dapat digunakan dengan mengabaikan asumsi-asumsi yang melandasi regresi parametrik. [4]

Diberikan data observasi $\left\{X_{i}, Y_{i}\right\}_{i=1}^{n}$ yang memenuhi regresi nonparametik, dengan $Y$ adalah variabel respon dan $X$ adalah variabel prediktor. Hubungan $Y$ dan $X$ tidak diketahui bentuk fungsinya, sehingga pencocokan kurva regresi bertujuan untuk mendapatkan hubungan antara variabel $X$ dan $Y$. Jika terdapat $n$ observasi independen, hubungan regresi dengan menggunakan model regresi nonparametik secara umum dimodelkan sebagai berikut : [5]

$$
Y_{i}=m\left(X_{i}\right)+\epsilon_{i}, i=1,2,3 \cdots . n
$$

dengan $m$ adalah fungsi penghalus atau pemulus (smoothing) yang belum diketahui bentuk kurvanya, $Y_{1}, \cdots, Y_{n}$ adalah data observasi dengan titik $X_{1}, \cdots, X_{n}$. Galat $\epsilon_{1}, \cdots, \epsilon_{n}$ adalah variabel random yang memiliki sebaran yang identik dan independen, dimana :

$$
\epsilon_{i} \sim N\left(0, \sigma^{2}\right), E\left(\epsilon_{i}\right)=0, \text { dan } \operatorname{var}\left(\epsilon_{i}\right)=\sigma^{2}>0, i=1,2, \cdots, n
$$




\subsection{Regresi Kernel Polinomial Lokal}

Teknik smoothing dengan pendekatan kernel sangat bergantung pada pemilihan fungsi kernel dan nilai bandwidth yang digunakan [5].

Definisi 2.1. [5] Didefinisikan $X$ adalah variabel random dengan distribusi kontinu $F(x)$ dan densitas $f(x)=\frac{d}{d x} F(x)$. Penduga densitas kernel untuk fungsi $f(x)$ adalah

$$
\widehat{f_{h}(x)}=\frac{1}{n h} \sum_{i=1}^{n} K\left(\frac{X_{i}-x}{h}\right)
$$

dengan

$$
\begin{aligned}
x & : \text { angka spesifik yang nilainya tetap } \\
h & : \text { bandwidth } \\
n & : \text { banyak data } \\
K & : \text { fungsi pembobot } \\
X_{i} & : \text { variabel prediktor ke- } i .
\end{aligned}
$$

Jika dinyatakan fungsi pembobot kernel yaitu $K_{h}(u)=\frac{1}{h} K\left(\frac{u}{h}\right)$ maka persamaan 2.2 dapat disederhanakan, menjadi

$$
\widehat{f}_{h}(x)=\frac{1}{n} \sum_{i=1}^{n} K_{h}\left(X_{i}-x\right)
$$

K pada kedua persamaan tersebut adalah fungsi kernel yang merupakan sebuah fungi kontinu, bernilai real, terbatas dan memenuhi $\int_{-\infty}^{\infty} K(x) d x=1, h$ adalah bilangan positif yang disebut bandwidth. Jika $K(u)$ adalah sebuah fungsi densitas kernel, maka $K_{h}(u)$ juga. [3]

\subsection{Penduga Kernel Polinomial Lokal}

Pada dasarnya pemodelan polinomial lokal menggunakan prinsip Deret Taylor, yang menyatakan bahwa setiap fungsi kontinu dapat secara lokal didekati dengan polinomial dari beberapa derajat. Misalkan $x$ merupakan lingkungan yang ditentukan yang berada pada sebuah interval atau yang dimaksud sebagai wilayah lokal, dimana fungsi $m\left(x_{i}\right)$ belum diketahui bentuk kurvanya, dan akan diduga menggunakan penduga polinomial lokal kernel [2]. Deret Taylor dapat digunakan sebagai asumsi dari $m\left(x_{i}\right)$, yaitu

$$
m\left(x_{i}\right) \approx m(x)+\left(x_{i}-x\right) m^{(1)}(x)+\frac{\left(x_{i}-x\right)^{2} m^{(2)}(x)}{2 !}+\cdots+\frac{\left(x_{i}-x\right)^{p} m^{(p)}(x)}{p !}
$$

Misalkan $\beta_{r}(x)=\frac{m^{(r)}(x)}{r !}$, dimana $r=1,2, \cdots, p$ maka persamaan (2.4) dapat ditulis menjadi:

$$
m\left(x_{i}\right) \approx \beta_{0}(x)+\left(x_{i}-x\right) \beta_{1}(x)+\cdots+\left(x_{i}-x\right)^{p} \beta_{p}(x)
$$


Dalam catatan matriks persamaan (2.5) dapat dinyatakan sebagai berikut :

$$
\mathbf{m}(\boldsymbol{x})=\mathbf{X} \boldsymbol{\beta}
$$

dimana $\mathbf{X}$ adalah matriks berukuran $\mathrm{n} \times(\mathrm{p}+1)$, dengan

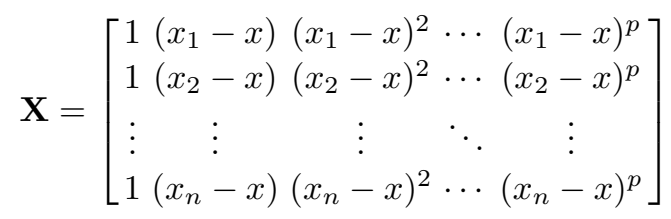

$\boldsymbol{\beta}$ adalah matriks berukuran $p+1 \times 1$ dengan

$$
\boldsymbol{\beta}=\left[\beta_{0}(x), \beta_{1}(x), \cdots, \beta_{p}(x)\right]^{T},
$$

dan

$$
\mathbf{m}(\mathbf{x})=\left[m\left(x_{1}\right), m\left(x_{2}\right), \cdots ., m\left(x_{n}\right)\right]^{T} .
$$

Misalkan

$$
\widehat{\boldsymbol{\beta}}=\left[\widehat{\beta_{0}}(x), \widehat{\beta_{1}}(x), \widehat{\beta_{2}}(x), \cdots, \widehat{\beta_{p}(x)}\right]^{T}
$$

merupakan penduga $\boldsymbol{\beta}$. Penduga ini diperoleh dengan menggunakan metode Weighted Least Square (WLS) dengan menjadikan fungsi kernel sebagai pembobot $[5]$.

\subsection{Pemilihan Bandwidth $h$}

Lebar jendela atau bandwidth (h) merupakan parameter pemulusan (smoothing) yang berfungsi untuk menentukan kemulusan dari kurva yang dihasilkan. Lebar jendela adalah besarnya lingkungan yang digunakan pada regresi kernel pada titik data dan memberikan nilai penimbangan setiap titik yang terletak di jendela. Jendela ini berfungsi untuk mengatur fungsi kernel sedemikian sehingga menghasilkan kurva yang mulus. Ketika bandwidth terlalu besar maka bias pemodelannya akan besar dan keragaman akan kecil. Ketika bandwidth yang terlalu kecil maka bias pemodelannya akan kecil dan keragaman akan besar. Oleh karena itu, pemilihan bandwidth yang optimal sangat penting menyeimbangkan bias dan keragaman agar diperoleh estimasi yang baik [5].

Untuk mendapatkan plot estimasi yang optimal harus digunakan bandwidth yang optimal pula. Beberapa metode pemilihan bandwidth yaitu Complete Cross Validation (CCV), Akaike Information Criterion (AIC), Generalized Cross Validation $(G C V)$, dan Bayesian Information Criterion (BIC).

Pemilihan bandwidth optimal pada penelitian ini dilakukan dengan metode Complete Cross Validation(CCV). Metode ini didasarkan pada estimasi turunan integrated squared density [5]. Dengan metode tersebut, bandwidth optimal adalah $h$ yang meminimumkan kriteria CCV, didefinisikan sebagai berikut.

$C C V(h, r)=R\left({\widehat{f_{h}}}^{(r)}\right)-\theta_{r}(h)+\frac{1}{2} \mu_{2}(K) h^{2} \theta_{r+1}(h)+\frac{1}{24}\left(6 \mu_{2}^{2}(K)-\delta(K)\right) h^{4} \theta_{r+2}(h)$ 
dengan

$$
\begin{aligned}
h & : \text { bandwidth } \\
r & : \text { orde derivatif } \\
\mu_{2}(K) & =\int x^{2} K(x) d x \\
R\left(K^{(r)}\right) & =\int K^{r}(x)^{2} d x \\
\delta(K) & =\int x^{4} K(x) d x . \\
R\left({\widehat{f_{h}}}^{(r)}\right) & =\frac{R\left(K^{(r)}\right)}{n h^{2 r+1}}+\frac{(-1)^{r}}{n(n-1) h^{2 r+1}} \sum_{i=1}^{n} \sum_{j=1}^{n} K^{(r)} * K^{(r)}\left(\frac{X_{j}-X i}{h}\right), j \neq i \\
\theta_{r}(h) & =\frac{(-1)^{r}}{n(n-1) h^{2 r+1}} \sum_{i=1}^{n} \sum_{j=1}^{n} K^{(2 r)}\left(\frac{X_{j}-X i}{h}\right), j \neq i .[5]
\end{aligned}
$$

\section{Pembahasan}

Pada bab ini akan dibahas mengenai pendekatan model regresi nonparametrik berdasarkan penduga polinomial lokal kernel dengan menggunakan kriteria Weighted Least Square (WLS) dengan nilai fungsi kernel sebagai pembobot yaitu fungsi kernel Gaussian dan pendekatan model dengan penduga kuadrat terkecil, serta memilih model terbaik antara penduga kernel polinomial lokal dan penduga kuadrat terkecil.

\subsection{Pemodelan Berat Badan Balita dengan Analisis Regresi Kuadrat Terkecil}

Metode Regresi Kuadrat Terkecil adalah metode yang digunakan untuk menentukan suatu hubungan linier dari suatu data agar dapat diprediksi nilai-nilainya yang mana nilai tersebut tidak terdapat pada data-data yang dimiliki. Model regresi kuadrat terkecil didefinisikan sebagai berikut.

$$
Y=\beta_{0}+\beta_{1} X
$$

Model regresi kuadrat terkecil menjadi

$$
\widehat{Y}=6,197682+(0,177296) X
$$

Bentuk kurva pertumbuhan dengan metode regresi kuadrat terkecil adalah sebagai berikut.

Nilai koefisien determinasi dari model ini adalah 93,144 persen. Model ini sebetulnya baik dalam memodelkan hubungan antara berat badan balita dengan umur, tetapi dapat dicari pemodelan lain yang lebih baik dan akurat.

\subsection{Pemodelan Berat Badan Balita dengan Regresi Kernel Polinomial Lokal}

Regresi kernel merupakan teknik pendugaan yang sesuai dengan bentuk data. Prinsip dasar dari regresi kernel adalah menggunakan fungsi terboboti yang disebut 


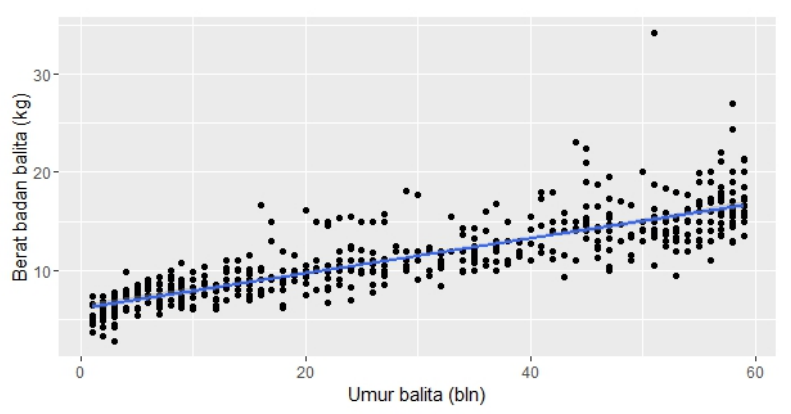

Gambar 1. Kurva pertumbuhan balita

dengan kernel lokal untuk setiap titik data pengamatan. Kernel akan menetapkan bobot untuk setiap lokasi berdasarkan jarak setiap data dari titik data tertentu yang dipilih, yang berfungsi untuk memperluas titik data asli menjadi titik data yang lebih kecil dengan langkah tertentu. Pada penentuan lebar jendela ini untuk mendapatkan titik data yang lebih kecil.

Langkah pertama pada regresi polinomial lokal kernel ini adalah melakukan pemilihan bandwidth optimal yaitu dengan metode CCV, serta menentukan fungsi kernel yaitu fungsi kernel Gaussian. Apabila nilai CCV yang diperoleh kecil maka nilai bandwidth yang dihasilkan adalah optimal [2], akan dicari menggunakan Sofware $R$. Dari 555 data didapatkan nilai bandwidth optimal adalah 3,059628, dengan menggunakan kriteria CCV diperoleh nilai $\widehat{y}$. Bentuk kurva pertumbuhan berat badan dan usia pada balita di Kota Padang tahun 2018 seperti pada Gambar 2.

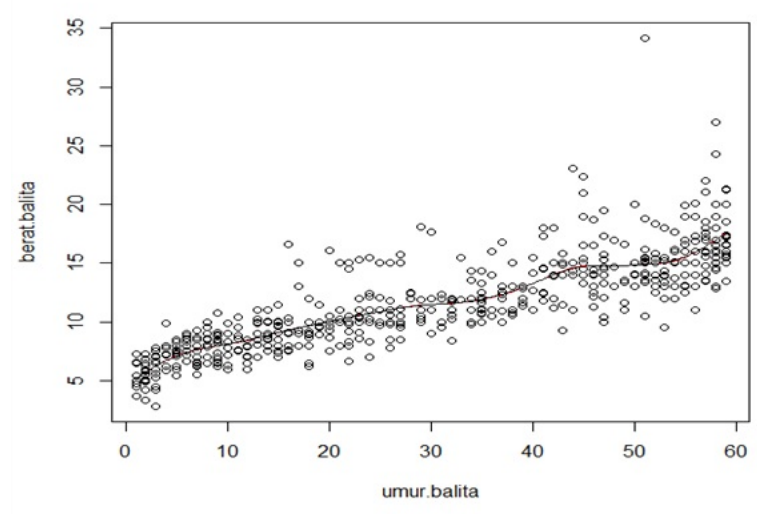

Gambar 2. Kurva pertumbuhan balita

Berdasarkan Gambar 2 dapat dijelaskan bahwa berat badan balita di Kota padang cukup tinggi pada interval umur 50 bulan sampai 59 bulan artinya pada interval umur tersebut, banyak balita yang memiliki berat badan yang tinggi. Hal 
ini secara tidak langsung memberikan arti bahwa balita di Kota Padang mendapat perlakuan gizi yang cukup serta pemantauan pertumbuhan yang dilakukan secara rutin. Akibatnya banyak balita sehat yang terhindar dari penyakit gizi buruk dan lain-lain. Nilai koefisien determinasinya adalah 95,4367 persen, serta plot datanya juga mengikuti bentuk data awal.

\subsection{Pemilihan Model Terbaik}

Untuk pemilihan model terbaik antara regresi kuadrat terkecil dan regresi polinomial lokal kernel dipilih berdasarkan kriteria koefisien determinasi pada masingmasing dugaan terhadap metode. Nilai koefisien determinasinya adalah 93,144 persen, sedangkan dengan menggunakan metode regresi polinomial lokal kernel didapatkan nilai koefisien determinasinya adalah 95,4367 persen.

Berdasarkan kriteria nilai koefisien determinasi adalah model yang baik yaitu model dengan nilai koefisien determinasi mendekati 1, nilai koefisien determinasi metode kuadrat terkecil adalah 0,93144 artinya 93 persen berat badan balita dipengaruhi oleh umur dan 7 persen dipengaruhi oleh faktor lingkungan dan nilai koefisien determinasi metode polinomial lokal kernel adalah 0,954367 artinya 95 persen berat badan balita dipengaruhi oleh umur dan 5 persen dipengaruhi oleh faktor lainnya seperti lingkungan dan lain-lain. Jadi metode regresi polinomial lokal kernel lebih baik dibandingkan dengan metode kuadrat terkecil untuk memodelkan hubungan antara berat badan balita dengan umur. Hal ini dapat dilihat pada gambar berikut.

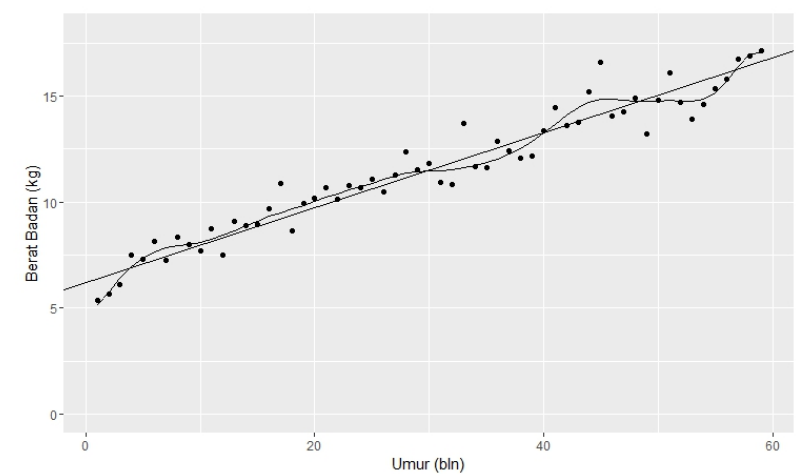

Gambar 3. Kurva Pertumbuhan Balita untuk kedua penduga

\section{Kesimpulan}

Berdasarkan hasil pengolahan data yang sudah dibahas pada bab pembahasan diperoleh model antara hubungan berat badan dan umur dengan 2 metode yaitu metode kuadrat terkecil dan metode regresi kernel polinomial lokal, dan diperoleh model terbaik adalah dengan menggunakan metode regresi kernel polinomial lokal 
karena memiliki nilai koefisien determinasi yang tinggi yaitu 0,954367 dan hampir mendekati 1. Pada model regresi kernel polinomial lokal dapat dilihat bahwa pertumbuhan balita terjadi sangat pesat pada interval umur 1-6 bulan, selanjutnya pada interval 7-50 bulan terjadi pertumbuhan yang cenderung melambat dan mengikuti bentuk data yang sebenarnya.

\section{Daftar Pustaka}

[1] Departemen Kesehatan RI. 2013. Riset Kesehatan Dasar. Jakarta, Badan Penelitian dan Pengembangan Kesehatan Kementrian Kesehatan RI

[2] Fan, J dan Gijbels,I. 1996. Local Polynomial and Its Aplications. New York, Chapman dan Hall

[3] Guidoum, AC. Kernel Estimator and Bandwidth Selection for Density and its Derivatives, The kedd Package, 2015

[4] Siegel, Sidney. 1992. Statistik Nonparametrik Untuk Ilmu-ilmu Sosial. Gramedia. Jakarta

[5] Silverman, BW. 1986. Density Estimation For Statistick and Data Analysis. New York : Chapman and Hall 